\title{
Study on Physical Function of Li and Han Nationality Students in China JiJin Sun ${ }^{1, a,{ }^{*}}$, Yan Sheng ${ }^{1, a}$ \\ ${ }^{1}$ Qiongtai teachers college, haikou,China \\ asjj2002033@163.com
}

Keywords: Education; P.E; Physical function; Minority nationality; Health;

\begin{abstract}
To study the physical function status of 7-12 years old Li nationality students, the work begins with two kinds of comparison,one is about Li nationality students' physical function in different years,the other is about the comparison of Li nationality students with national Han nationality students,the comparison indexes about pulse,SBP,DBP,vital capacity,etc.The investigate time is $1985,1995,2000,2005,2010$,etc. With the comparison of the average level of physical function,find that Li nationality students' physical function has a tendency of descend to recovery,but the resting heart rate,DBP are lasting increase.In the comparison of different nationality students,the Li nationality students' performance is not good,neither in pulse,nor in blood pressure,and even in vital capacity.In the mainly time,Li nationality students is higher in pulse,and lower in blood pressure(SBP/DBP) and vital capacity.but to make anyone consolation is, that the gap between them is changing into small,except the pulse.So the society should take a persistent concern in Li nationality students' nutrition,habitation and P.E to promote their physical function.
\end{abstract}

\section{Introduction}

Since 1985, Chinese government began a investigation of physical fitness and health research of Chinese school students.and then,there have been held on 7 times,the interval of two neighboring investigations is almost 5 years[1].Now begins the study with a opened data about physical and health research, which includes Chinese Han nationality and minority nationality,try to learn the characteristic of Chinese Li nationality's physical function.

\section{Research objects and methods}

Research objects. The objects include 7-18 years old Li nationality students, which the number is 1200 , and Han nationality students is 1800 .

Research methods. The main methods include literature,survey,measurement and statistics.and the measurement indexes are pulse,blood pressure and vital capacity.

In the comparison of data,the main comparison object is average level[2], which the original data comes from Chinese government's opened reports of physical fitness and health research of Chinese school students[2,3,4,5,6].

\section{Results}

Comparison of Pulse Changes in Different Periods of Li Nationality Students. Table 1 and Fig .1 shows, in a monitor of 25 years,Li nationality school boy's resting heart rate shows a lasting increase trend.especially in 2010,compared with the last,the resting heart added 8.08 times per minute.While that Li nationality school girl 's resting heart rate shows a extraordinary tendency,it shows decreased trend in the beginning,from 1985 to 2010 , or to the year of 2005,it is decreased,but at last,in 2010, it shows the same tendency to school boy,the resting heart rate increased 9.87 times per minute. 
Table 1 Changes of Li nationality pulse in different history periods (time/min )

\begin{tabular}{llll}
\hline \multirow{2}{*}{ Gender } & Difference & & \\
\cline { 2 - 4 } & $1985-2000$ & $1985-2005$ & $1985-2010$ \\
\hline male & 3.04 & 1.41 & 8.08 \\
female & -0.32 & -2.18 & 9.87 \\
\hline
\end{tabular}

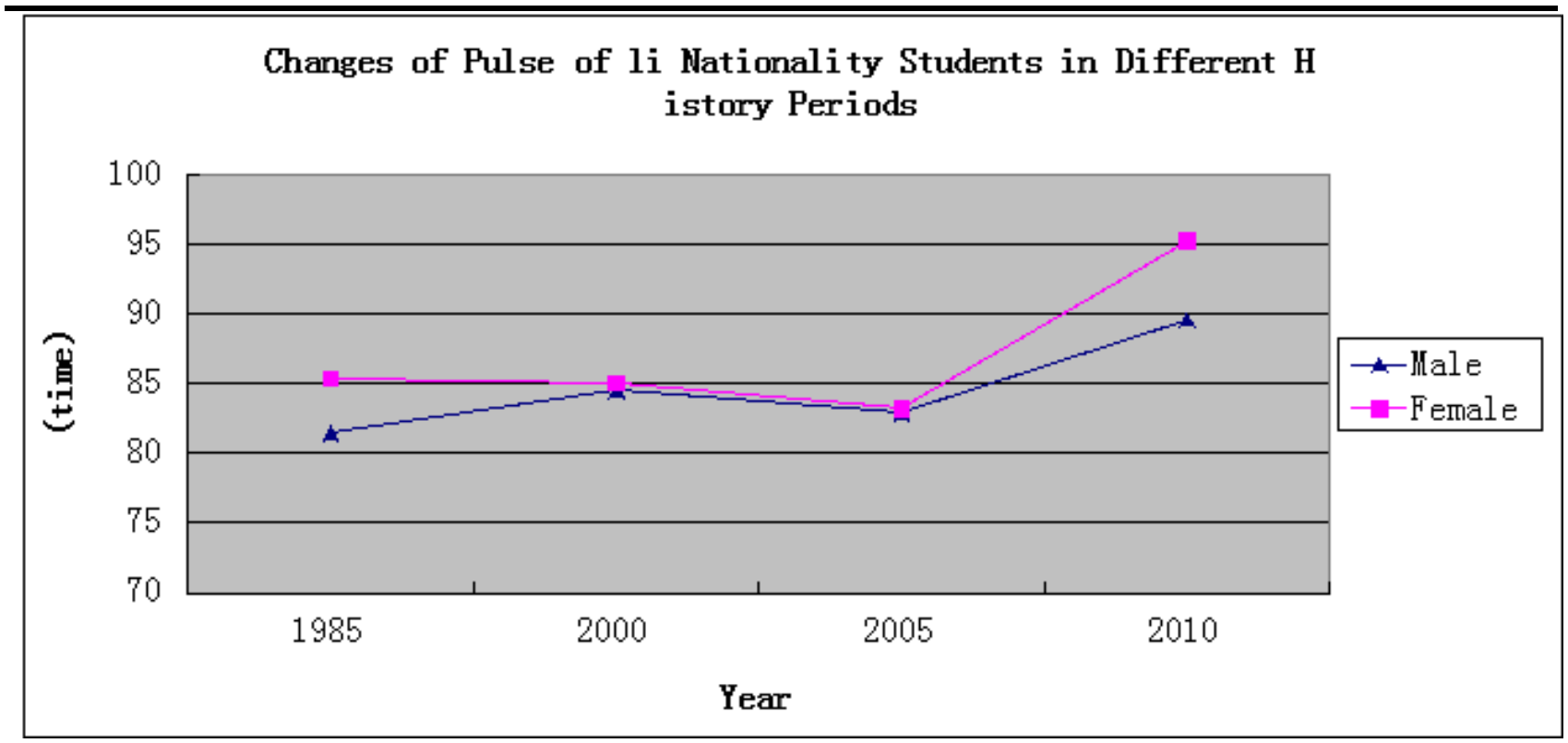

Figure. 1

Comparison in Pulse Change of Li and Han Students. From the Table 2 and Table 3,in10 years ago,the difference between $\mathrm{Li}$ and Han nationality students is small,but in recent 5 years,Li nationality is far exceeds the Han nationality, it's even exceed over 6 to 11 times per minute,the data is surprised.

Table 2 Comparison in pulse of $\mathrm{Li}$ and Han rural school boys (time/min)

\begin{tabular}{lllll}
\hline Subject & Average & & \\
\cline { 2 - 5 } & 1985 & 2000 & 2005 & 2010 \\
\hline Li nationality school boy & 81.48 & 84.52 & 82.89 & 89.56 \\
National rural school boy & 81.95 & 83.59 & 83.66 & 83.22 \\
Difference & -0.47 & 0.93 & -0.77 & 6.34 \\
\hline
\end{tabular}

Table 3 Comparison in pulse of Li Han rural school girls $\quad$ (time/min )

\begin{tabular}{lllll}
\hline \multirow{2}{*}{ Subject } & Average & & \\
\cline { 2 - 5 } & 1985 & 2000 & 2005 & 2010 \\
\hline Li nationality school girl & 85.39 & 85.07 & 83.21 & 95.26 \\
National rural school girl & 83.98 & 84.98 & 84.67 & 84.29 \\
Difference & 1.41 & 0.09 & -1.46 & 10.97 \\
\hline
\end{tabular}

Comparison in Blood Pressure in Different Periods of Li Nationality Students. From the first monitor,SBP of Li nationality students is decreased gradually,not only in 1995,but also in 2000, and in 
2005.but in 2010,the tendency make a change,school boys of Li shows a increase of 3.82, and school girls shows a slow decrease(from the Table 4,Fig .2).

In DBP,compare with the year of 1985,the DBP average level of Li nationality is rise.Before 2000 , the ascending tendency is fast,but after 2000, the ascending tendency is slow.

Table 4 Changes of Li nationality students blood pressure in different history periods $(\mathrm{mm} \mathrm{Hg})$

\begin{tabular}{ccccc}
\hline \multirow{2}{*}{ Gender } & \multicolumn{4}{c}{ Difference in SBP/DBP } \\
\cline { 2 - 5 } & $1985-1995$ & $1985-2000$ & $1985-2005$ & $1985-2010$ \\
\hline male & $-5.01 / 12.29$ & $-3.51 / 20.03$ & $-4.58 / 18.97$ & $3.82 / 16.43$ \\
female & $-6.59 / 10.00$ & $-5.83 / 17.27$ & $-8.86 / 12.76$ & $-1.19 / 13.99$ \\
\hline
\end{tabular}

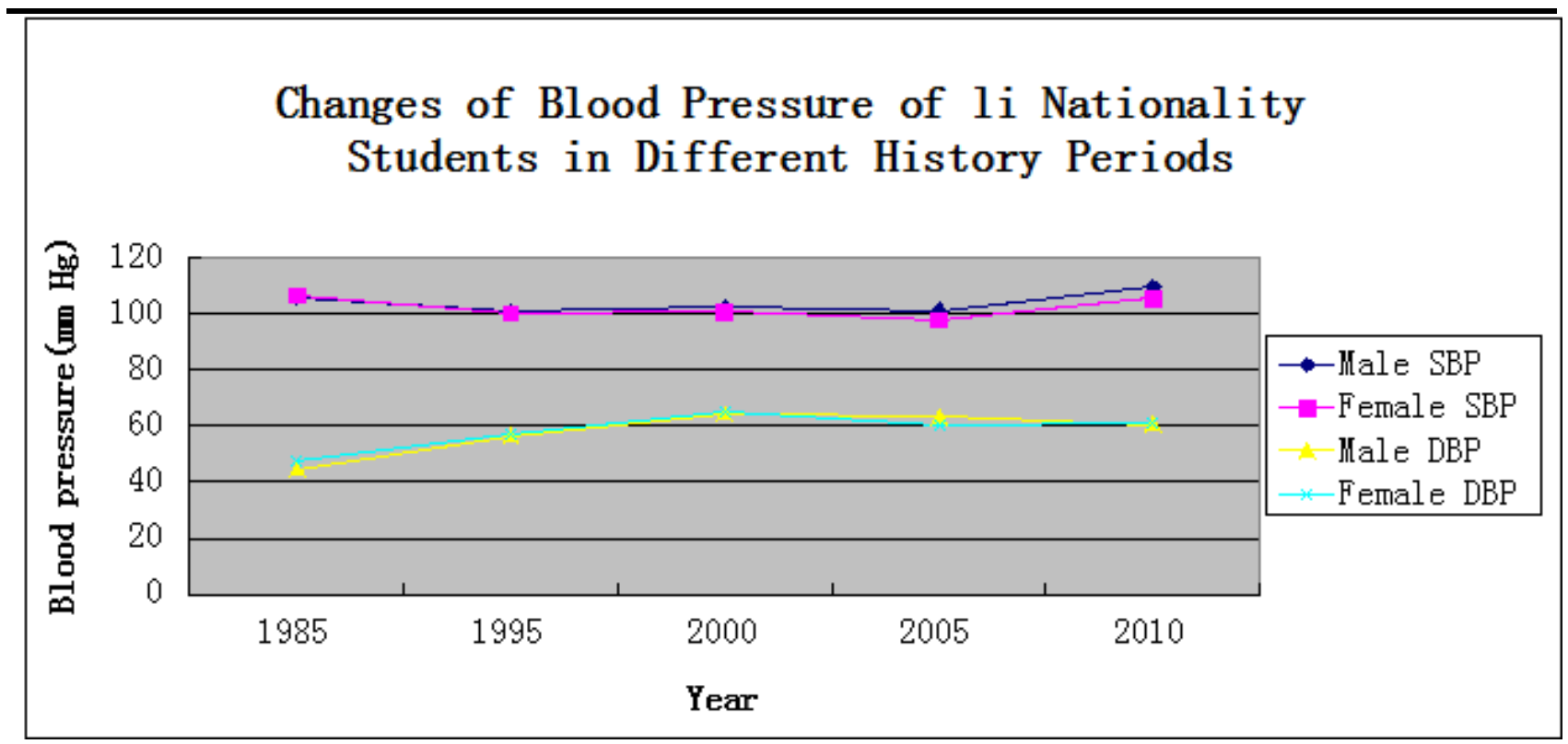

Figure. 2

Comparison in Changes of Blood Pressure of Li and Han Students. Compared with whole national average level,the male Li nationality students is always the lower in SBP,but in 2010,the average level of school boy of Li nationality is higher than that of national rural school boy In DBP,the tendency of lower of Li nationality school boy isn't changed in 25 years.only in the years of 2000 and 2005,the difference between them is smaller than other time(from Table 5).

Table 5 Comparison in blood pressure of $\mathrm{Li}$ and Han rural school boys $\quad \mathrm{mm} \mathrm{Hg}$ )

\begin{tabular}{cccccc}
\hline Subject & \multicolumn{5}{c}{ SBP/DBP } \\
\cline { 2 - 6 } & 1985 & 1995 & 2000 & 2005 & 2010 \\
\hline $\begin{array}{c}\text { LI nationality school } \\
\text { boy }\end{array}$ & $105.90 / 44.29$ & $100.89 / 56.58$ & $102.39 / 64.32$ & $101.32 / 63.26$ & $109.72 / 60.72$ \\
$\begin{array}{c}\text { National rural school } \\
\text { boy }\end{array}$ & $107.24 / 52.82$ & $106.43 / 63.42$ & $105.05 / 65.62$ & $103.92 / 64.01$ & $105.69 / 65.31$ \\
Difference & $-1.34 /-8.53$ & $-5.54 /-6.84$ & $-2.66 /-1.3$ & $-2.6 /-0.75$ & $4.03 /-4.59$ \\
\hline
\end{tabular}

The same tendency can seen in the female.From Table 6,from 1995 to 2005,in ten years,Li nationality school girl is lower than national rural school girl in SBP.but in 2010,the tendency appears turn over,Li nationality school girl is higher than national rural school girl.In DBP,like boys,Li nationality school girl is lower in all times. 
Not only the boys, but also the girls, the difference between Li and national rural students is change into smaller.The same can be see from2011.[7]

Table 6 Comparison in blood pressure of $\mathrm{Li}$ and Han rural school girls $\quad(\mathrm{mm} \mathrm{Hg})$

\begin{tabular}{cccccc}
\hline \multirow{2}{*}{ Subject } & \multicolumn{5}{c}{ SBP/DBP } \\
\cline { 2 - 6 } & 1985 & 1995 & 2000 & 2005 & 2010 \\
\hline Li nationality school girl & $106.80 / 47.51$ & $100.21 / 57.51$ & $100.97 / 64.77$ & $97.94 / 60.27$ & $105.61 / 61.50$ \\
National rural school girl & $106.52 / 54.81$ & $104.75 / 63.56$ & $102.60 / 65.07$ & $100.97 / 63.22$ & $102.30 / 64.37$ \\
Difference & $0.28 /-7.3$ & $-4.54 /-6.05$ & $-1.63 /-0.3$ & $-3.03 /-2.95$ & $3.31 /-2.87$ \\
\hline
\end{tabular}

Comparison in Changes of Vital Capacity in Different Periods of Li Nationality Students. From the year of 2010,in the last 25 years, the Li nationality students' vital capacity is descending year and year.but in 2014, when after a 30-year descending,the average level begin to rise(from Table 7,Fig .3).

Table 7 Changes of vital capacity of Li nationality students in different history periods $(\mathrm{ml})$

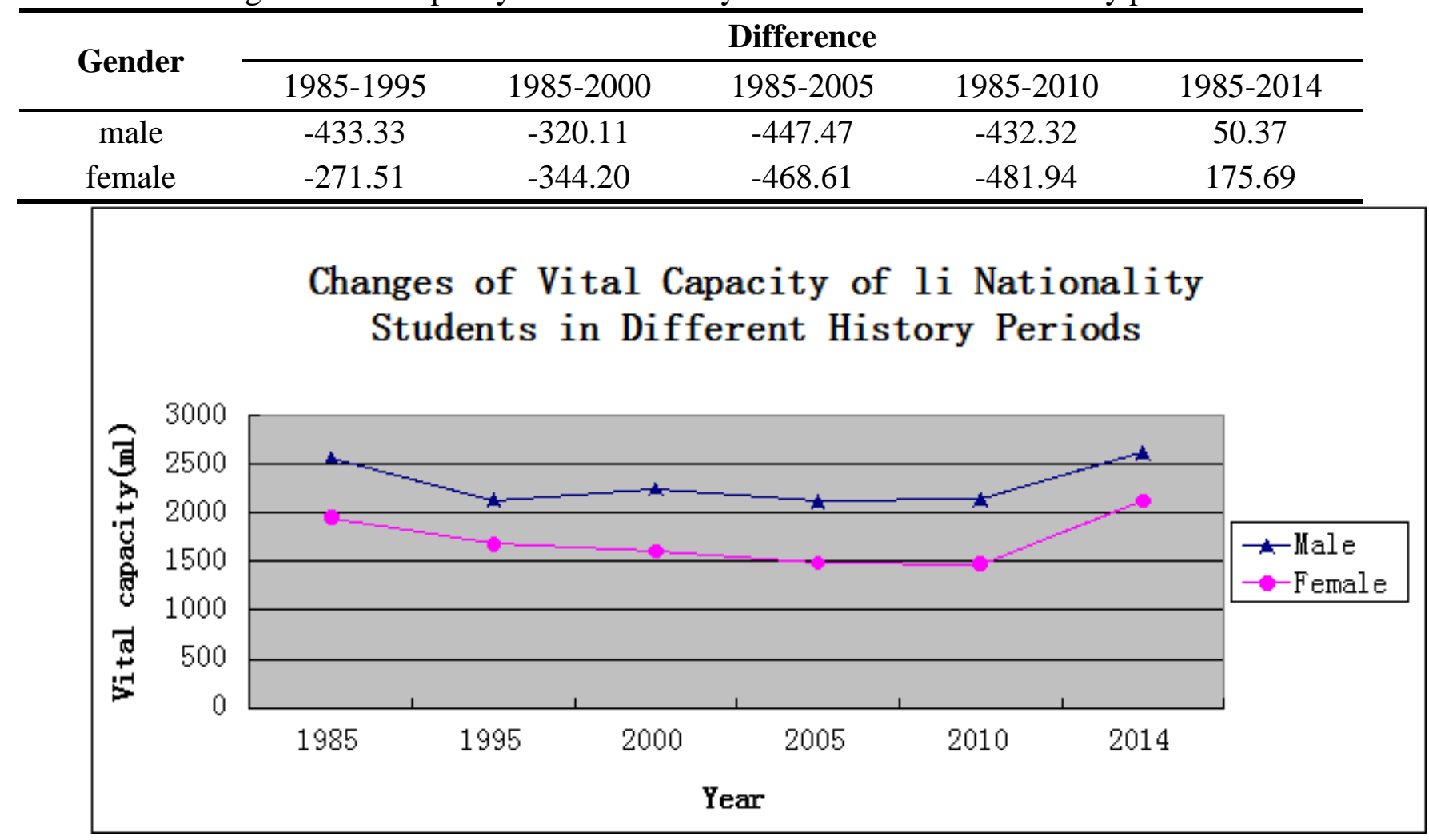

Figure. 3

Comparison in Vital Capacity of Li and Han Students. In the comparison of vital capacity,the Li nationality students is always lower than national rural Han students.but the difference is smaller than the last time,especially in the male students(from Table 8,Table 9). This standpoint can be seen in historical documents.[8,9,10] 
Table 8 Comparison in vital capacity of Li and Han rural school boys $\quad(\mathrm{ml})$

\begin{tabular}{ccccccc}
\hline Subject & \multicolumn{6}{c}{ Average } \\
\cline { 2 - 7 } & 1985 & 1995 & 2000 & 2005 & 2010 & 2014 \\
\hline Li nationality school boy & 2571.00 & 2138.00 & 2251.00 & 2124.00 & 2139.00 & 2621.00 \\
National rural school boy & 2518.00 & 2440.00 & 2443.00 & 2206.00 & 2302.00 \\
Difference & 53.00 & -302.00 & -192.00 & -82.00 & -163.00 & \\
\hline
\end{tabular}

Table 9 Comparison in vital capacity of Li and Han rural school girls $\quad(\mathrm{ml})$

\begin{tabular}{ccccccc}
\hline \multirow{2}{*}{ Subject } & \multicolumn{6}{c}{ Average } \\
\cline { 2 - 7 } & 1985 & 1995 & 2000 & 2005 & 2010 & 2014 \\
\hline Li nationality school girl & 1956.00 & 1684.00 & 1612.00 & 1487.00 & 1474.00 & 2131.00 \\
National rural school girl & 2091.00 & 1969.00 & 1937.00 & 1678.00 & 1759.00 & \\
Difference & -135.00 & -285.00 & -325.00 & -191.00 & -285.00 & \\
\hline
\end{tabular}

\section{Conclusion}

In 30 years,Li nationality students has a rapid increase in physical function. The indexes shows a tendency of descend to recovery.But the resting heart rate and DBP show a lasting increase trend. Compared with the national rural students, $\mathrm{Li}$ nationality students' average level is lower,but in the main indexes, the gap is decreased,except the pulse.

The whole society and the local government should remain a persistent concern in Li nationality students' nutrition, habitation and P.E, which is the best way to change the physical function rapidly.

\section{Acknowledgements}

This work is supported by foundation of 2011 Research Project of Qiongtai Teachers College of China.

\section{References}

[1] W.T.Hao,S.G.Ni and S.J.Cai,The Research on Physical Health of Students in Hainan Province (Guangming Daily Press,China2010).(In Chinese)

[2] Research team:2010 Reports on the Physical Fitness and Health Research of Chinese School Students(Higher Education Press,China2012).(In Chinese)

[3] Research team:2005 Reports on the Physical Fitness and Health Research of Chinese School Students(Higher Education Press,China2007).(In Chinese)

[4] Research team:2000 Reports on the Physical Fitness and Health Research of Chinese School Students(Higher Education Press,China2002).(In Chinese)

[5] Research team:1995 Reports on the Physical Fitness and Health Research of Chinese School Students(Jilin science and Technology Press,China1996).(In Chinese)

[6] Research team:1985 Reports on the Physical Fitness and Health Research of Chinese School Students,(Higher Education Press,China1987).(In Chinese)

[7] Z.Y.Huang:Journal of New Journal.(2011)No.1,p.16.(In Chinese)

[8] Y.Wang,Z.Y.Yang and C.Z.Yuan:Journal of Hainan normal University(Natural Science) .Vol.15 (2002)No.2,p.92-97.(In Chinese) 
[9] P.J.Hu, C.Y.Ji:Journal of China School Health.Vol.26(2005)No.1,p.13-15.(In Chinese)

[10] Z.B.Zhang,J.J.Zhang:Acta Anthropologica Sinica,Vol.1(1982)No.1,p.53-69.(In Chinese) 